\title{
Statins, 3-hydroxy-3-methylglutaryl
} coenzyme A reductase inhibitors, potentiate the anti-angiogenic effects of bevacizumab by suppressing angiopoietin2, BiP, and Hsp90 $\alpha$ in human colorectal cancer

\author{
S J Lee ${ }^{1,3}, \mathrm{ILee}^{2,3}, \mathrm{~J} \mathrm{Lee}^{1}, \mathrm{C}$ Park${ }^{2}$ and W K Kang ${ }^{\star, 1}$ \\ ${ }^{1}$ Division of Hematology-Oncology, Department of Medicine, Samsung Medical Center, Sungkyunkwan University School of \\ Medicine, Seoul 135-710, Korea and 'Biomedical Research Institute, Samsung Medical Center, Seoul 135-710, Korea
}

Background: Statins, 3-hydroxy-3-methylglutaryl coenzyme A reductase inhibitors, are commonly prescribed because of their therapeutic and preventive effects on cardiovascular diseases. Even though they have been occasionally reported to have antitumour activity, it is unknown whether statins have anti-angiogenic effect in human colorectal cancer (CRC).

Methods: A total of 11 human CRC cell lines were used to test the effects of bevacizumab, statins, and bevacizumab plus statins on human umbilical vein endothelial cell (HUVEC) viability and invasion in vitro. To determine the molecular mechanism of statins as anti-angiogenic agents, we performed an angiogenesis antibody array and proteomics analysis and confirmed the results using immunoblot assay, HUVEC invasion rescue assay, and siRNA assay. The antitumoural effects of bevacizumab and statins were evaluated in xenograft models.

Results: A conventional dose of statins (simvastatin $0.2 \mu \mathrm{M}$, lovastatin $0.4 \mu \mathrm{M}$, atorvastatin $0.1 \mu \mathrm{M}$, and pravastatin $0.4 \mu \mathrm{M}$ ) in combination with bevacizumab directly reduced the cell viability, migration, invasion, and tube formation of HUVECs. The culture media of the CRC cells treated with bevacizumab or statins were also found to inhibit HUVEC invasion by suppressing angiogenic mediators, such as angiopoietin2, binding immunoglobulin protein (BiP), and Hsp90 $\alpha$. The combined treatment with bevacizumab and simvastatin significantly reduced the growth and metastases of xenograft tumours compared with treatment with bevacizumab alone.

Conclusions: The addition of simvastatin at a dose used in patients with cardiovascular diseases (40-80 mg once daily) may potentiate the anti-angiogenic effects of bevacizumab on CRC by suppressing angiopoietin2, BiP, and Hsp90 $\alpha$ in cancer cells. A clinical trial of simvastatin in combination with bevacizumab in patients with CRC is needed.

Because of their need for oxygen and nutrients for survival, mammalian cells are located within 100 to $200 \mu \mathrm{m}$ of blood vessels-the diffusion limit for oxygen (Folkman, 1971). For multicellular organisms to grow beyond this size, they must recruit new blood vessels by vasculogenesis and angiogenesis. This process is regulated by a balance between pro- and anti-angiogenic

*Correspondence: Professor WK Kang; Email: wkkang@skku.edu
${ }^{3}$ These authors contributed equally to this work.

Revised 7 April 2014; accepted 30 April 2014; published online 19 June 2014

(c) 2014 Cancer Research UK. All rights reserved 0007 - 0920/14 
molecules and is usually derailed in cancer (Folkman, 2007). Without blood vessels, tumours cannot grow beyond a critical size or metastasise to another organ.

Angiogenesis is a complex process that includes endothelial cell proliferation and movement, as well as endothelial cell-mediated degradation of the extracellular matrix (ECM). The multistep process of angiogenesis is essential for cancer progression and metastasis. Vascular endothelial growth factor (VEGF), a critical mediator of angiogenesis, is usually upregulated in cancer (Ferrara, 2002). Bevacizumab, which is a humanised monoclonal immunoglobulin G1 antibody that targets circulating VEGF, has been shown to improve response rates and survival when combined with any first-line or second-line standard cytotoxic chemotherapy regimen in patients with metastatic colorectal cancer (Hurwitz et al, 2004; Giantonio et al, 2007; Grothey et al, 2008; Van Cutsem et al, 2009). However, bevacizumab does not result in marked survival improvements, and further, its clinical activity depends on the presence of specific resistance profiles. To overcome these limitations and also uncover novel therapeutic approaches, it is necessary to elucidate resistance mechanisms and identify agents that potentiate this targeting agent.

Statins are widely used as lipid-lowering agents to reduce cardiovascular risk with a favourable safety profile. Statins, such as lovastatin, simvastatin, pravastatin, and atorvastatin, are potent inhibitors of 3-hydroxy-3-methylglutaryl coenzyme A reductase, which is the rate-controlling enzyme of the mevalonate pathway. Mevalonate is the initial molecule for a diverse array of end products, such as farnesyl pyrophosphate and geranylgeranyl pyrophosphate, both of which are essential substrates for posttranslational modifications of Ras and Ras homologue (Rho). Ras and Rho have important roles in the intracellular signal transduction that is responsible for cell growth, proliferation, migration, and survival (Goldstein and Brown, 1990; Casey, 1995). On the basis of the effect of statins on post-transcriptional modifications of Ras and Rho, the antitumour effect of statins has been suggested in various cancer cell lines (Kim et al, 2001; Park et al, 2001; Lee et al, 2006).

The relationship between statins and angiogenesis has been investigated, and interestingly, the effects of statins were found to depend on their blood concentration (Weis et al, 2002). At low nanomolar concentrations, statins have pro-angiogenic effects and are regarded as beneficial for treating cardiovascular diseases (Dimmeler et al, 2001; Llevadot et al, 2001; Assmus et al, 2003; Spyridopoulos et al, 2004). On the other hand, at high micromolar concentrations, they have anti-angiogenic activity and may be of special significance for cancer therapy. The anticancer effects of statins have been shown to result from the inhibition of endothelial cell proliferation and migration, as well as the induction of apoptosis (Negre-Aminou et al, 1997; Pirillo et al, 1997; Sato et al, 1998; Kaneta et al, 2003; Muck et al, 2004; Schaefer et al, 2004); however, a limitation in using statins for cancer therapy is that the required doses are too high to be applied to patients.

We previously studied the effects of statins at cardiovascular therapeutic doses in cancer cell lines in vitro (Lee et al, 2006, 2011). Our results showed that $0.3 \mu \mathrm{m}$ lovastatin induced cell senescence in prostate cancer cells (Lee et al, 2006), and that addition of $0.2 \mu \mathrm{M}$ simvastatin to cetuximab reduced the proliferation of CRC cells carrying KRAS mutations (Lee et al, 2011). In this present study, we investigated whether cardiovascular therapeutic doses of statins affect angiogenesis and potentiate anti-angiogenic effects of bevacizumab in CRC. On the basis of several previous results (Sato et al, 1998; Kaneta et al, 2003; Muck et al, 2004; Schaefer et al, 2004; Lee et al, 2006), we postulated that the statin dose used had little direct effect on endothelial cells; therefore, we focused on the mediators of angiogenesis. The mechanism underlying the antiangiogenic effects of statins was evaluated by angiogenesis antibody array and proteomics analysis. The effects of drugs on tumour growth were also tested in mouse xenograft models.

\section{MATERIALS AND METHODS}

Reagents and antibodies. Cell culture medium (RPMI-1640, DMEM) and serum (fetal bovine serum (FBS)) were purchased from Invitrogen (Gaithersburg, MD, USA). Simvastatin, atorvastatin, lovastatin, and pravastatin were purchased from Sigma-Aldrich (St Louis, MO, USA). Calcein-AM was from BD Biosciences (San Jose, CA, USA), and generic chemicals were purchased from Sigma-Aldrich. The Proteome Profiler Human Angiogenesis Antibody Array Kit was purchased from R\&D Systems (Minneapolis, MN, USA). Angiopoietin 2 siRNAs were purchased from Dharmacon (Lafayette, CO, USA). Binding immunoglobulin protein (BiP) and $\mathrm{Hsp} 90 \alpha$ siRNAs were purchased from Qiagen (Valencia, CA, USA). Angiopoietin 2, BiP, and Hsp90 $\alpha$ active protein were purchased from Abcam (Cambridge, UK). The rabbit polyclonal anti-angiopoietin 2 antibody was purchased from Abfrontier (Seoul, Korea), mouse monoclonal anti-BiP antibody from BD Biosciences (San Jose, CA, USA), rat monoclonal anti-Hsp90 $\alpha$ antibody from Stressgen (Victoria, BC, Canada), mouse monoclonal anti-CD31 antibody from Dako (Glostrup, Denmark), and mouse monoclonal anti-BrdU antibody from Roche (Mannheim, Germany).

Cell lines and cell culture. We used 11 known human CRC cell lines, CoLo320, DiFi, NCI-H716, SW48, HT29, RKO, WiDr, DLD1, HCT8, LS174T, and SW403. Most of these cell lines were purchased from American Type Culture Collection (Manassas, VA, USA), except for the DiFi cell line that was generously provided by Dr JO Park (Samsung Medical Center, Seoul, Korea). All cell lines were grown in RPMI-1640 medium supplemented with $10 \%$ FBS and antibiotics (Invitrogen Corporation, Carlsbad, CA, USA). Human umbilical vein endothelial cells (HUVECs) were purchased from the American Type Culture Collection and grown in endothelial cell growth medium-2 (Lonza, Walkersville, MD, USA).

Preparation of conditioned media. CRC cells were seeded at a concentration of $5 \times 10^{5}$ cells per $60-\mathrm{mm}$ dish (Corning Costar Corp., Corning, NY, USA) and incubated with $0.2 \mu \mathrm{m}$ simvastatin or bevacizumab $0.25 \mathrm{mg} \mathrm{ml}^{-1}$. The conditioned medium was collected after $72 \mathrm{~h}$ of incubation and centrifuged at $2000 \mathrm{~g}$ for $10 \mathrm{~min}$, and aliquots of cultured medium were stored at $-80^{\circ} \mathrm{C}$ before analysis. The conditioned medium was used for the HUVEC viability and invasion assay.

Cell viability assay. Cell viability experiments were carried out using fluorescent dye (calcein-AM, BD Biosciences, San Jose, CA, USA). Calcein-AM was taken up by the cells, and intracellular esterases cleaved the acetomethylester (AM) moiety to generate free fluorescent calcein, which was measured at 485-nm excitation and 520-nm emission.

For evaluation of the direct effects of statins on HUVEC viability, HUVECs were plated at a density of $1 \times 10^{4}$ cells per well in 96-well plates, to which was added $0.2 \mu \mathrm{M}$ simvastatin in combination with the appropriate dose of bevacizumab $(0,0.125$, $0.25,0.5$, or $1 \mathrm{mg} \mathrm{ml}^{-1}$ ). After $24 \mathrm{~h}$, the cells were stained. In addition, the experiments with other statins of relatively equivalent dose and $0.2 \mu \mathrm{M}$ simvastatin $(0.4 \mu \mathrm{m}$ lovastatin, $0.1 \mu \mathrm{M}$ atorvastatin or $0.4 \mu \mathrm{M}$ pravastatin) were performed to determine whether these statins had a similar effect to simvastatin.

For evaluation of the indirect effect of statins via angiogenesis mediators, HUVECs were plated at a density of $1 \times 10^{4}$ cells per well in 96-well plates (HUVEC culture media $100 \mu \mathrm{l}$ ). After $24 \mathrm{~h}$, colon cancer conditioned media $100 \mu \mathrm{l}$ were added to the wells, 
and the cells were further cultured for $24 \mathrm{~h}$. The cells were stained with fluorescent dye ( $1 \mu \mathrm{M}$ calcein-AM, $30 \mathrm{~min})$. The fluorescence of the cells was measured by a Victor 1420 multi-label counter (Wallac, Boston, MA, USA) ( $\lambda$ ex $485 \mathrm{~nm}, \lambda \mathrm{em} 535 \mathrm{~nm}$ ). The experiments were performed three times. In addition, to determine which specific phase of the cell cycle was affected by simvastatin and bevacizumab, we conducted a bromodeoxyuridine (BrdU) assay. CRC cells (CoLo320) were incubated with $0.2 \mu \mathrm{m}$ simvastatin or bevacizumab $0.25 \mathrm{mg} \mathrm{ml}^{-1}$ for $24 \mathrm{~h}$. One hour before the end of the drug treatment, BrdU (Sigma-Aldrich) was added to the cells at a final concentration of $10 \mu \mathrm{M}$ for $1 \mathrm{~h}$. After incubation, the cells were treated as described elsewhere (Vivo et al, 2003). Briefly, cells were trypsinised, washed in PBS, fixed in 70\% ethanol, and resuspended in $2 \mathrm{~N} \mathrm{HCl}$ at room temperature for $30 \mathrm{~min}$. After washing with $0.5 \%$ Tween 20 in PBS (PBST), cells were centrifuged and rinsed until the $\mathrm{pH}$ settled between 7.2 and 7.4, and then the cells were incubated with BrdU antibodies (Dako, Glostrup, Denmark) diluted $1: 10$ in PBST at room temperature for $1 \mathrm{~h}$, followed by two washes with PBST. The pelleted cells were then resuspended and incubated for $30 \mathrm{~min}$ at room temperature in anti-mouse IgG antibodies (Dako, Glostrup, Denmark) conjugated with fluorescein isothiocyanate, diluted 1:20 in PBST. After two washes, cells were stained with propidium iodide $\left(0.05 \mu \mathrm{g} \mathrm{ml}^{-1}\right)$ and RNase $\mathrm{A}\left(1 \mu \mathrm{g} \mathrm{ml}^{-1}\right)$ for $30 \mathrm{~min}$ at $37^{\circ} \mathrm{C}$ in the dark. In total, 10000 cells were analysed with a flow cytometer FACSCalibur (BD Biosciences, Heidelberg, Germany) with CellQuest Pro software (BD Biosciences, Heidelberg, Germany).

Modified Boyden chamber cell invasion assay. The in vitro HUVEC invasion assay was performed using BioCoat Matrigel Invasion Chambers (Corning Costar Corp.). To prepare the co-culture system using a double chamber method, $1 \times 10^{5}$ colon cancer (for evaluating the direct effects on HUVEC) cells or $600 \mu \mathrm{l}$ of colon cancer cell media (for evaluating the indirect effects via mediators) were seeded in a 24-well plate (the lower chamber) and cultured overnight. Human umbilical vein endothelial cells $\left(5 \times 10^{4}\right.$ cells) treated with or without $0.2 \mu \mathrm{M}$ simvastatin or $0.25 \mathrm{mg} \mathrm{ml}^{-1}$ bevacizumab (only HUVECs for evaluating the indirect effects) were seeded in Matrigel-precoated transwell chambers that consisted of polycarbonate membranes with $8-\mu \mathrm{m}$ pores. Transwell chambers were then placed in 24-well plates. After a 24-h incubation, the upper surfaces of the transwell chambers were wiped with a cotton swab, and invading cells were fixed and stained with a $0.05 \%(\mathrm{w} / \mathrm{v})$ crystal violet solution. Invading cells in five random microscopic fields $(\times 200)$ were counted, and experiments were performed three times in triplicate.

Tube formation assay. In vitro angiogenesis was assessed using the Endothelial Tube Formation Assay Kit (CBA-200; Cell Biolabs, Inc., San Diego, CA, USA). Briefly, the ECM gel was thawed at $4{ }^{\circ} \mathrm{C}$ overnight and then bottom coated in a 96 -well plate $(50 \mu \mathrm{l}$ per well) at $37^{\circ} \mathrm{C}$ for $30 \mathrm{~min}$. Next, $150 \mu \mathrm{l}$ of media containing HUVECs $\left(1 \times 10^{6}\right.$ cells $)$ with or without $0.2 \mu \mathrm{m}$ simvastatin or $0.25 \mathrm{mg} \mathrm{ml}^{-1}$ bevacizumab was added to each well on top of the solidified ECM gel and incubated at $37^{\circ} \mathrm{C}$ for $18 \mathrm{~h}$. Tubes were subsequently stained with the fluorescent dye ( $1 \mu \mathrm{M}$ calcein-AM) for $30 \mathrm{~min}$. Images were taken using an Axiovert 200 fluorescence microscope (Zeiss, Jena, Germany).

Angiogenesis-related protein antibody array. To study the mechanism of angiogenesis inhibited by simvastatin, the Proteome Profiler Human Angiogenesis Antibody Array Kit (R\&D Systems) was used according to the manufacturer's instructions. The Human Angiogenesis Antibody Array Kit detects 55 different angiogenesisrelated proteins (activin A, ADAMTS-1, angiogenin, angiopoietin1, angiopoietin2, angiostatin, amphiregulin, artemin, coagulation factor III, CXCL16, DPPIV, EGF, EG-VEGF, endoglin, endostatin, endothelin-1, FGF acidic, FGF basic, FGF-4, FGF-7, GDNF,
GM-CSF, HB-EGF, HGF, IGFBP-1, IGFBP-2, IGFBP-3, IL-1 $\beta$, IL-8, LAP, leptin, MCP-1, MIP-1 $\alpha$, MMP-8, MMP-9, NRG1- $\beta 1$, PTX3, PD-ECGF, PDGF-AA, PDGF-AB, persephin, PF4, prolactin, serpin B5, serpin E1, serpin F1, TIMP-1, TIMP-4, thrombospondin-1, thrombospondin-2, uPA, vasohibin, VEGF, and VEGF-c). Briefly, membranes were blocked with array buffer 7 and then incubated with colon cancer conditioned media of CoLo320, NCI-H716, and SW48 cells overnight at $4{ }^{\circ} \mathrm{C}$. The membranes were washed three times with $1 \times$ wash buffer and incubated with the streptavidin-HRP (1:5000 dilution) for $30 \mathrm{~min}$. After three washes of $10 \mathrm{~min}$ each, the membranes were incubated with the ECL Western Blotting Detection System (GE Healthcare, Buckinghamshire, UK) and exposed to X-ray film.

Two-dimensional gel electrophoresis. CRC cells (NCI-H716 and SW48) were incubated with $0.2 \mu \mathrm{M}$ simvastatin for $48 \mathrm{~h}$ in RPMI1640 medium with $10 \%$ FBS, which was then replaced with $0.2 \mu \mathrm{M}$ simvastatin in serum-free medium for an additional $24 \mathrm{~h}$. Culture media were collected and concentrated. For 2D electrophoresis, one milligram of protein was loaded onto a nonlinear IPG Drystrip (pH 3-10, 7 cm, Amersham Biosciences, San Francisco, CA, USA), and then focusing was carried out for a total of $75 \mathrm{kVh}$. The strips were subsequently placed on top of vertical $10 \%$ sodium dodecyl sulphate (SDS)-polyacrylamide gels and subjected to electrophoresis using the Miniprotean III Bio-Rad system (Bio-Rad, Hercules, CA, USA). The resulting gels were visualised by staining with silver stain solution (Amersham Biosciences). Silver-stained protein spots were excised from $2 \mathrm{D}$ gels and identified by mass spectrometry.

Immunoblot analysis. CRC cells (CoLo320, DiFi, DLD1, LS174T, NCI-H716, RKO, SW48, and SW403) were seeded at a concentration of $5 \times 10^{5}$ cells per $60-\mathrm{mm}$ dish. On the next day, cells were incubated with $0.2 \mu \mathrm{m}$ simvastatin for an additional 3 days. Cells were lysed in ice-cold lysis buffer (20 mM HEPES ( $\mathrm{pH} 7.4$ ), $1 \%$ Triton X-100, $1 \mathrm{~mm}$ EDTA, $1 \mathrm{~mm} \mathrm{MgCl}_{2}, 150 \mathrm{~mm} \mathrm{NaCl}$, $10 \%$ glycerol, and protease inhibitor cocktail). Cell lysates were also prepared from frozen xenograft tumours (three tumours per treatment group) grown in mice, which were homogenised and lysed in glass homogenizers (Kontes Glass Co, Vineland, NJ, USA) in ice-cold lysis buffer. Lysates were centrifuged at $15000 \mathrm{~g}$ at $4{ }^{\circ} \mathrm{C}$ for $10 \mathrm{~min}$. Equal amounts of proteins $(20 \mu \mathrm{g}$ per well $)$ from the clarified lysates were separated by SDS-polyacrylamide gel electrophoresis and transferred to a nitrocellulose membrane of $0.45-\mu \mathrm{m}$ pore size (Whatman, Maidstone, UK). The membranes were sequentially incubated in 5\% dry milk with antibodies against Angiopoietin 2 (Abfrontier), BiP (BD Biosciences, San Jose, CA, USA) and Hsp90 $\alpha$ (Stressgen), and with HRP-conjugated secondary antibodies (Santa Cruz Biotechnologies, Santa Cruz, CA, USA). The ECL system was used for detection (Invitrogen Corporation).

RNA interference and transfection. CoLo320, DLD1, and RKO cells $\left(4 \times 10^{5}\right.$ cells per $60-\mathrm{mm}$ dish $)$ were transiently transfected with $20 \mathrm{~nm}$ siRNAs (Angiopoietin 2:Dharmacon, BiP and Hsp90 $\alpha$ :Qiagen) using HiPerFect Transfection Reagent (Qiagen) according to the manufacturer's instructions and were used for immunoblot analysis $48 \mathrm{~h}$ after transfection. The sequences of the siRNAs used in this study were as follows: control nontargeting siRNA (5'-UAGCGACUAAACACAUCAA- $\left.3^{\prime}\right)$, angiopoietin2targeted siRNA (si-Angiopoietin 2) (5'-ACAAAUAAGUUCAACG GCA-3 ${ }^{\prime}$ ), BiP-targeted siRNA (si-BiP) (5'-UAGGGUGUGUGUUC ACCUUCA- $3^{\prime}$ ), and Hsp90 $\alpha$-targeted siRNA (si-Hsp90 $\alpha$ ) (5'-AAC CCUGACCAUUCCAUUAUU- $3^{\prime}$ ).

Xenograft study. Male BALB/c nude mice, $4-6$ weeks old $(n=5$ per cell line per treatment group), were implanted subcutaneously with DiFi $\left(5.0 \times 10^{6}\right)$, NCI-H716 $\left(5.0 \times 10^{6}\right)$, DLD1 $\left(5.0 \times 10^{6}\right)$, or SW403 $\left(5.0 \times 10^{6}\right)$ cells in $100 \mu$ volume. Each mouse received two subcutaneous injections in the bilateral flank for the development 
of 2 tumours (10 tumours per treatment group). One week after implantation, mice ( $n=5$ mice per cell line per treatment group) were assigned into four groups-PBS only, bevacizumab, simvastatin, or a combination of bevacizumab and simvastatin. The mice were treated twice per week with intraperitoneal injection of $2.5 \mathrm{mg} \mathrm{kg}^{-1}$ bevacizumab in PBS and/or once daily with oral $2 \mathrm{mg} \mathrm{kg}^{-1}$ simvastatin dissolved in DW. Tumour diameters were measured with a digital caliper (Proinsa, Vitoria, Spain) every 2-3 days, and tumour volumes were calculated using the following formula: $V=(L \times W 2) / 2$, where $V=$ volume (in cubic millimetres), $L=$ length (in millimetres), and $W=$ width (in millimetres). The mice were killed, and the tumours (three tumours per treatment group) were resected and frozen in liquid nitrogen until later use for immunoblot analyses. All mice experiments were conducted in accordance with the Institute for Laboratory Animal Research Guide for the Care and Use of Laboratory Animals, and the protocols were approved by the appropriate Institutional Review Boards at Samsung Medical Center (Agreement-20130102004).

For the syngeneic peritoneal dissemination model, $1.0 \times 10^{7}$ DLD1 cells were inoculated intraperitoneally into male BALB/c nude mice. On the following day, the mice $(n=5$ mice per cell line per treatment group) were assigned into four groups-PBS only, bevacizumab, simvastatin, or a combination of bevacizumab and simvastatin. The mice were treated twice per week with intraperitoneal injection of $2.5 \mathrm{mg} \mathrm{kg}$ bevacizumab in PBS and/or once daily with oral $2 \mathrm{mg} \mathrm{kg}^{-1}$ simvastatin dissolved in DW. After 4 weeks, animals were killed, and tumour nodules were counted.

Immunohistochemistry. Formalin-fixed tissue samples were embedded in paraffin using standard histologic procedures.

After deparaffinisation and rehydration, $4-\mu \mathrm{m}$ sections on silane-coated slides were used for immunohistochemistry. Slides were incubated with primary antibodies (angiopoietin2 ( $1: 200$ dilution), BiP ( $1: 150$ dilution), Hsp90 $\alpha$ ( $1: 2000$ dilution), and CD31 (1:20 dilution) antibody) in a humidified chamber overnight at $4{ }^{\circ} \mathrm{C}$, washed, and incubated with biotinylated secondary antibodies (Dako, Carpinteria, CA, USA).

Statistical analysis. The mean tumour volume in each mouse of each cell line was computed for growth curves (the mean tumour volume in each group $=$ total volume from all mice per treatment group divided by number of mice in that group). The statistical significance of the differences between treatment groups for cell growth and tumour volume was calculated using Student's $t$-test. All $P$-values $<0.05$ were considered to be statistically significant. All statistical tests were two sided.
A

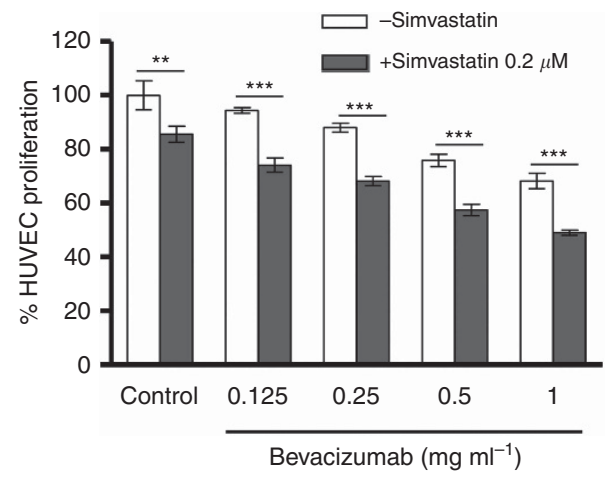

B

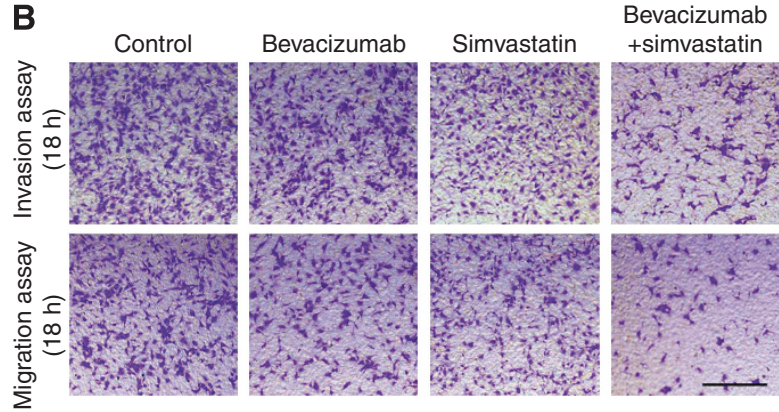

C

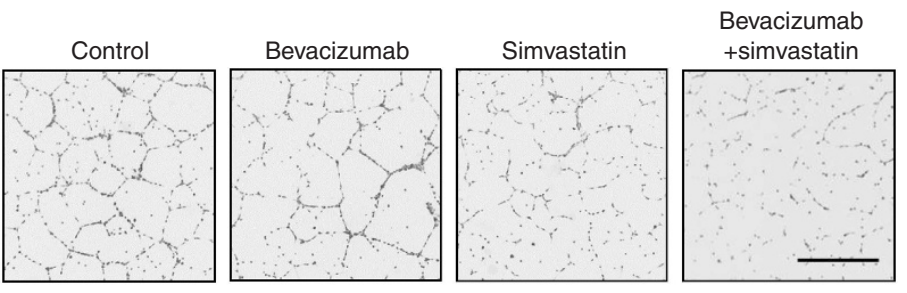

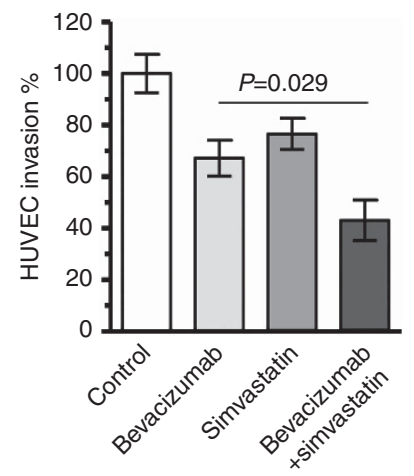

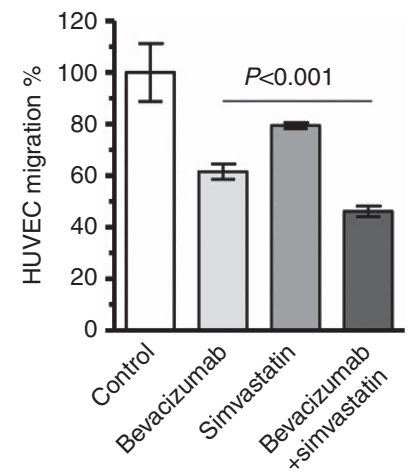

Figure 1. Simvastatin directly inhibits HUVEC viability, migration, invasion, and tube formation in vitro. (A) Cell viability assay of HUVECs treated with $0.2 \mu \mathrm{M}$ simvastatin in addition to various doses of bevacizumab $\left(0,0.125,0.25,0.5\right.$, or $\left.1 \mathrm{mg} \mathrm{ml}^{-1}\right)$. At $24 \mathrm{~h}$ after treatment, cells were stained with fluorescent dye $(1 \mu \mathrm{M}$ calcein-AM) for $30 \mathrm{~min}$. Results of the cell count are expressed as the percentage of cell viability using the control PBS as a reference $\left({ }^{\star *} P=0.003,{ }^{\star \star \star} P<0.001\right)$. (B) Invasion and migration assays using a double chamber method. A total of $1 \times 10^{5}$ colon cancer cells were seeded in a 24-well plate (the lower chamber) and cultured overnight, and HUVECs $\left(5 \times 10^{4}\right.$ cells) treated with or without $0.2 \mu \mathrm{M} \mathrm{simvastatin}$ or $0.25 \mathrm{mg} \mathrm{ml}^{-1}$ bevacizumab were seeded in Matrigel-precoated transwell chambers. Transwell chambers were then placed in 24-well plates. After 24-h incubation, upper surfaces of transwell chambers were wiped with a cotton swab, and invading cells were fixed and stained with a $0.05 \%$ ( $\mathrm{w} / \mathrm{v}$ ) crystal violet solution. Results of the cell count are expressed as the percentage of cell invasion using the control PBS as a reference. Addition of simvastatin to bevacizumab treatment induced a statistically significant decrease in HUVEC invasion (HUVEC invasion, $P=0.029 ;$ HUVEC migration, $P<0.001$ ). (C) Tube formation assay of HUVECs treated with or without $0.2 \mu \mathrm{m}$ simvastatin or $0.25 \mathrm{mg} \mathrm{ml}^{-1}$ bevacizumab. The ECM gel was thawed at $4{ }^{\circ} \mathrm{C}$ overnight and then bottom coated in a 96 -well plate at $37^{\circ} \mathrm{C}$ for $30 \mathrm{~min}$. Next, $150 \mu \mathrm{l}$ of media containing HUVECs $\left(1 \times 10^{6}\right.$ cells $)$ treated with or without $0.2 \mu \mathrm{m}$ simvastatin or $0.25 \mathrm{mg} \mathrm{ml}^{-1}$ bevacizumab was added to each well on top of the solidified ECM gel and incubated at $37^{\circ} \mathrm{C}$ for $18 \mathrm{~h}$. Tubes were subsequently stained with the fluorescent dye ( $1 \mu \mathrm{m}$ calcein-AM) for $30 \mathrm{~min}$ (size bar, $400 \mu \mathrm{m}$ ). 


\section{RESULTS}

Effects of bevacizumab and simvastatin on in vitro HUVEC viability, migration, invasion, and tube formation. As endo thelial cell proliferation is important and necessary for angiogenesis, we investigated the inhibitory effect of simvastatin on the growth of endothelial cells. Our results indicate that simvastatin inhibited HUVEC viability and also potentiated the inhibitory effect of bevacizumab on the growth of HUVECs (Figure 1A). We repeated the same set of experiments with different lipid-lowering agents at relatively equivalent doses, including $0.4 \mu \mathrm{m}$ lovastatin, $0.1 \mu \mathrm{m}$ atorvastatin, and $0.4 \mu \mathrm{m}$ pravastatin, and observed similar inhibitory effects to those of simvastatin on HUVEC viability (see Supplementary Figure 1). BrdU assay results demonstrated that simvastatin in combination with bevacizumab induced G1 arrest (see Supplementary Figure 2).

We next performed Boyden chamber migration and invasion assays because migration and invasion are two key steps for the formation of new blood vessels during angiogenesis processes. The results demonstrate that simvastatin not only inhibited HUVEC migration and invasion, but also showed an additive effect to that of bevacizumab (invasion assay, $P=0.029$; migration assay, $P<0.001$; Figure 1B). As endothelial cells can spontaneously form a 3D tubular capillary-like network on Matrigel cultures, we also performed a tube formation assay. As shown in Figure 1C, although simvastatin alone was able to inhibit HUVEC tube formation, the combination with bevacizumab almost completely suppressed tube formation.

Cell viability and invasion assays of HUVECs treated with CRC cell culture media. We used culture media of CRC cells that were treated with bevacizumab or simvastatin, under the assumption that the anti-angiogenic effect of simvastatin is based on not only a direct effect on endothelial cells, but also an indirect effect on CRC cells. Compared with the control group, no significant decrease in HUVEC viability was observed in the bevacizumab, simvastatin, or combination group for any of 11 CRC cell lines tested (CoLo320, DiFi, NCI-H716, SW48, HT29, RKO, WiDr, DLD1, HCT8, LS174T, and SW403) (Figure 2A).

On the other hand, we found that the conditioned medium from bevacizumab treatment inhibited HUVEC invasion in all 11 CRC cells, and that simvastatin potentiated the anti-invasive effect of bevacizumab in 9 CRC cell lines, excluding SW48 and HCT8, in which simvastatin had no effect on HUVEC invasion (Figure 2B). The $P$-value shown in Figure $2 \mathrm{~B}$ was calculated based on the comparison of the bevacizumab-only group with the bevacizumab and simvastatin combination group.

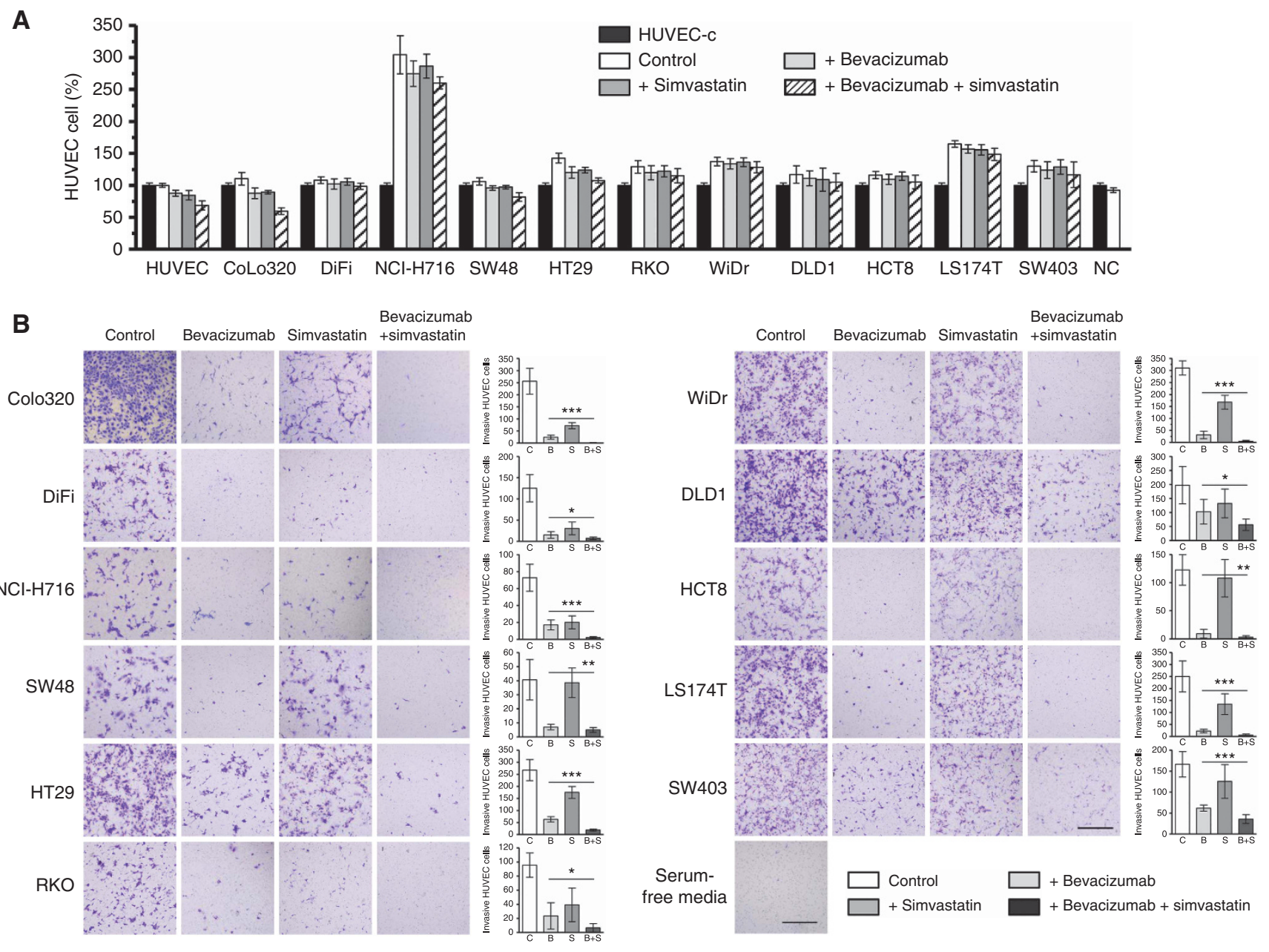

Figure 2. CRC cells were incubated with $0.2 \mu \mathrm{m}$ simvastatin or $0.25 \mathrm{mg} \mathrm{ml}^{-1}$ bevacizumab for 3 days. Conditioned media were then collected and tested using HUVEC viability and invasion assays. (A) Neither bevacizumab nor simvastatin affected HUVEC viability in any of 11 CRC cell lines. Results of the cell count are expressed as the percentage of cell viability using the control PBS (HUVEC-c) as a reference. (B) Conditioned media treated with simvastatin potentiated the anti-invasive effect of bevacizumab in nine CRC cell lines, except SW48 and HCT8 (size bar, $400 \mu$ m; $\left.{ }^{\star} P=0.01-0.05,{ }^{\star \star \star} P<0.001,{ }^{\star \star} P>0.05\right)$. 
We also assessed whether other statins have similar effects on HUVEC invasion using DLD1 cells and found that $0.4 \mu \mathrm{M}$ lovastatin, $0.1 \mu \mathrm{M}$ atorvastatin, and $0.4 \mu \mathrm{M}$ pravastatin, which are doses equivalent to $0.2 \mu \mathrm{M}$ simvastatin, had similar inhibitory effects on HUVEC invasion (see Supplementary Figure 3).

Angiogenesis antibody array and 2D-gel electrophoresis using CRC cell culture media. Among 11 CRC cell lines, we selected CoLo320 and NCI-H716, both of which were very sensitive to simvastatin, as well as SW48, which was resistant to simvastatin, in the HUVEC invasion assay of conditioned media. The conditioned media of these three CRC cells treated with or without simvastatin were analysed using the angiogenesis antibody array, and then the results were compared. With simvastatin treatment, angiopoietin2 was found to be significantly reduced in CoLo320 and NCI-H716, whereas it was slightly increased in SW48 (see Supplementary Figure 4a). Two-dimensional gel electrophoresis and mass spectrometry also revealed a two- or three-fold decrease in $\mathrm{BiP}$ and Hsp $90 \alpha$ when NCI-H716 cells were treated with simvastatin (see Supplementary Figure 4b). To determine whether angiopoietin2, $\mathrm{BiP}$, and $\mathrm{Hsp} 90 \alpha$, which were decreased by simvastatin treatment, are key mediators of angiogenesis, we performed immunoblot, HUVEC invasion rescue, and siRNA assays. In the immunoblot assay, angiopoietin 2 and $\mathrm{Hsp} 90 \alpha$ were decreased in all eight CRC cells after simvastatin treatment, whereas $\mathrm{BiP}$ also tended to be decreased, except in RKO, SW48, and SW403 (Figure 3A). In the HUVEC invasion rescue assay, all four CRC cells treated with simvastatin showed a decreased anti-HUVEC invasion effect after addition of angiopoietin2, $\mathrm{BiP}$, and $\mathrm{Hsp} 90 \alpha$ proteins (Figure $3 \mathrm{~B}$ ). When CRC cells were transfected with siRNAs of angiopoietin2, $\mathrm{BiP}$, and $\mathrm{Hsp} 90 \alpha$, the culture media were found to inhibit HUVEC invasion (Figure 3C).

Effects of simvastatin and bevacizumab on CRC growth in vivo. To determine whether the enhanced anti-angiogenic action of the drug combination could also be observed in vivo, we implanted DiFi, NCI-H716, DLD1, or SW403 cells into mice and assigned them to the following four groups ( $n=5$ mice per cell line per treatment group): untreated control, bevacizumab, simvastatin, or combination of bevacizumab and simvastatin. Each mouse received two subcutaneous injections in the bilateral flank for the development of 2 tumours (10 tumours per treatment group). In all cases, the combination of bevacizumab and simvastatin resulted in significantly reduced tumour volumes compared with results for bevacizumab alone (Figure 4A; for DiFi tumours, bevacizumab vs combination, mean tumour volume on day $15,283.6 \mathrm{~cm}^{3}$ vs $116.8 \mathrm{~cm}^{3}$; mean difference, $166.8 \mathrm{~cm}^{3} ; 95 \% \mathrm{CI}, 56.2-277.3$; $P=0.005)$.

Next, the xenograft tumours were extirpated, and protein expression was analysed as follows. We performed immunohistochemistry for CD31, an endothelial cell marker, angiopoietin2, $\mathrm{BiP}$, and $\mathrm{Hsp} 90 \alpha$, which were characterised by the angiogenesis antibody array and 2D-gel electrophoresis. As shown in Figure 4B, the expression levels of CD31, angiopoietin2, BiP, and Hsp90 $\alpha$ were lowest in the bevacizumab and simvastatin combination group. The immunoblot analysis shown in Figure 4C

A

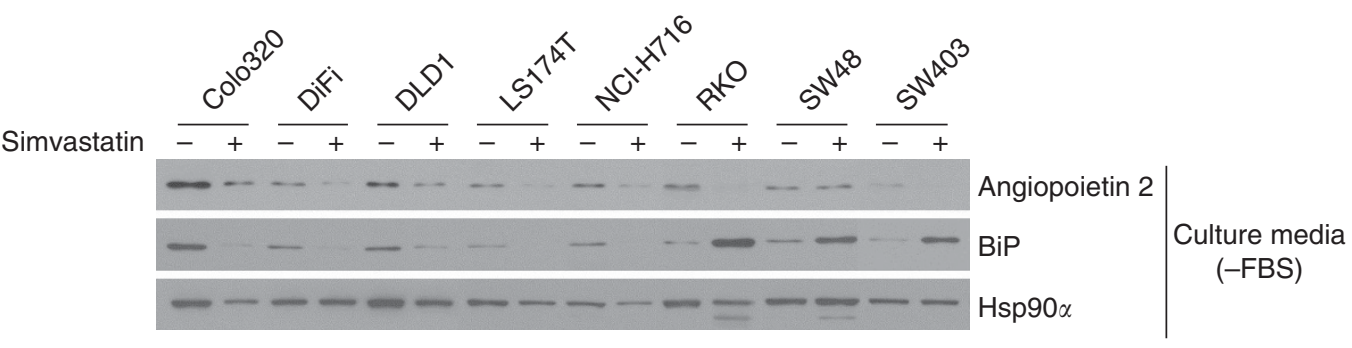

B

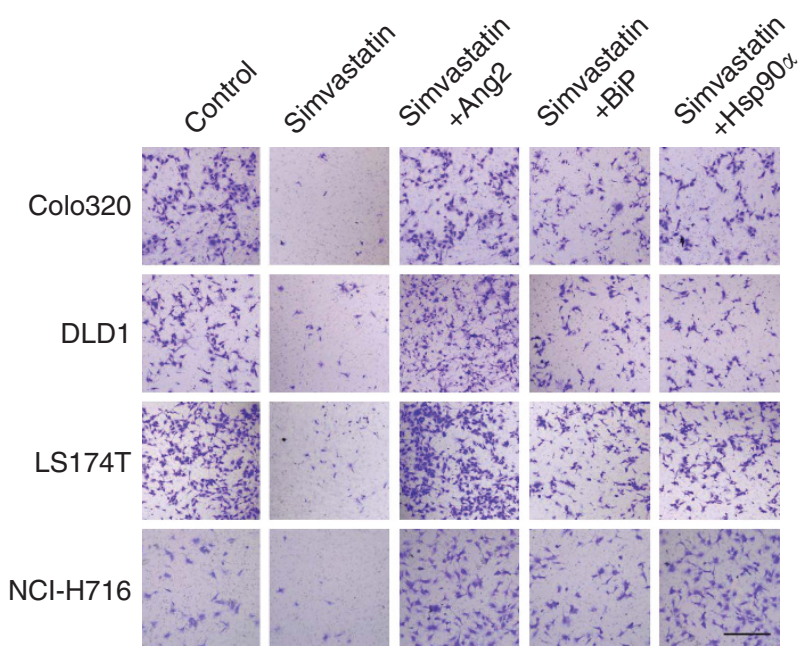

C

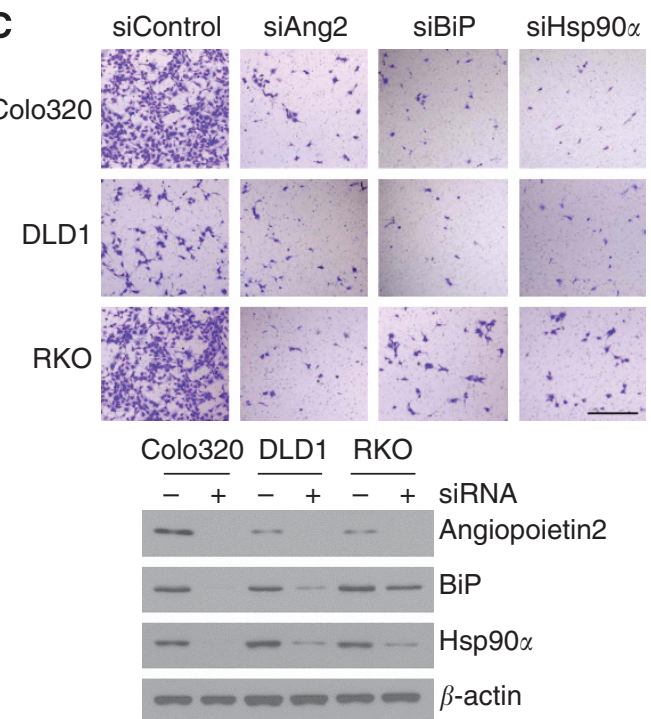

Figure 3. Angiopoietin2, BiP, and $\mathrm{Hsp} 90 \alpha$ are key mediators of the anti-angiogenic effect of simvastatin. (A) CRC cells were incubated with $0.2 \mu \mathrm{M}$ simvastatin for 3 days, and cell lysates were subjected to the immunoblot assay. Angiopoietin2 and Hsp90 $\alpha$ were decreased in all eight CRC cells, and BiP also tended to decrease, except in RKO, SW48, and SW403. (B) HUVEC invasion assay using conditioned media, and HUVEC invasion assay after addition of angiopoietin2 (Ang2) $\left(0.1 \mu \mathrm{g} \mathrm{ml}^{-1}\right), \mathrm{BiP}\left(1 \mu \mathrm{g} \mathrm{ml}^{-1}\right)$, or $\mathrm{Hsp} 90 \alpha\left(1 \mu \mathrm{g} \mathrm{ml}^{-1}\right)$ active protein. Addition of these proteins reversed the anti-angiogenic effect of simvastatin. (C) Conditioned media of CRC cells transfected with 20 nM siRNAs suppressed HUVEC invasion. The immunoblot analysis confirmed loss of angiopoietin2, BiP, and Hsp90 $\alpha$ protein expression (size bar, $400 \mu \mathrm{m}$ ). 
A
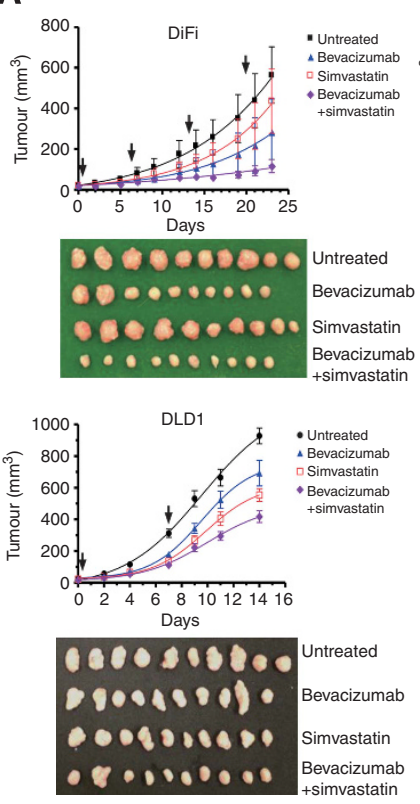

- Untreated A Bevacizumab
$\square$ Simvastatin - Bevacizumab
+simvastatin
A nvastatin

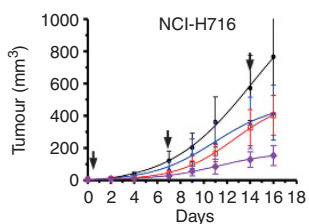

Days

C

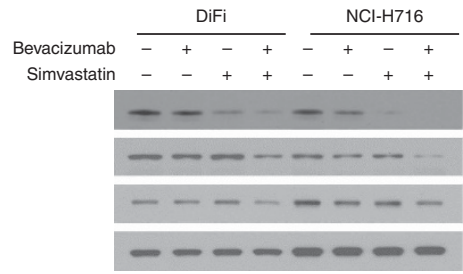

B
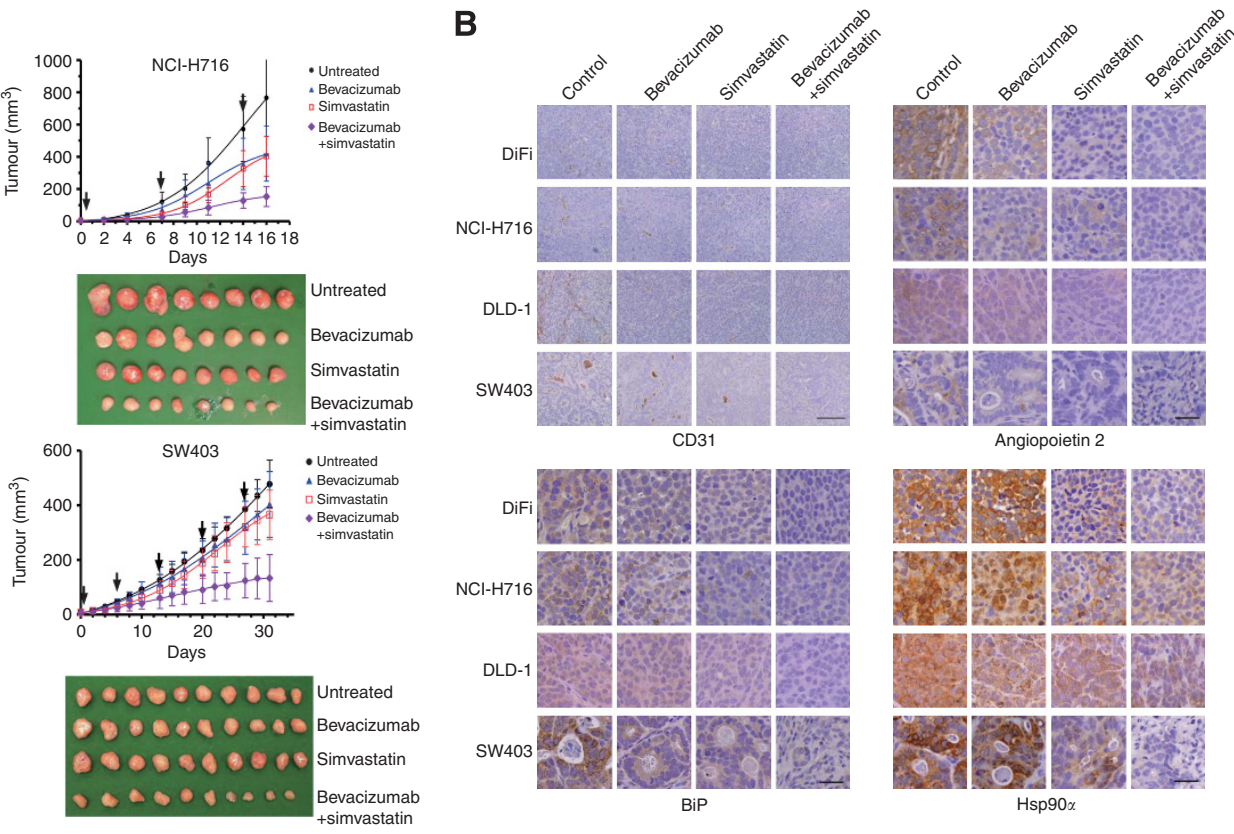

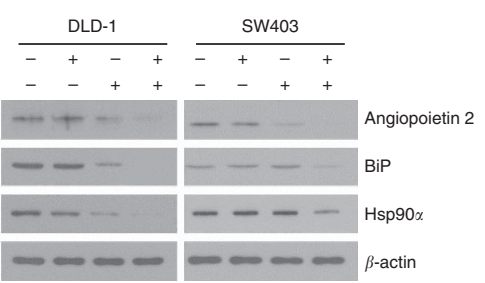

Figure 4. Effects of bevacizumab and simvastatin combination therapy on tumour growth in vivo. BALB/c nude mice were injected subcutaneously in the bilateral flank with DiFi, NCl-H716, DLD1, or SW403 cells. The mice were treated twice per week with an intraperitoneal injection of $2.5 \mathrm{mg} \mathrm{kg}^{-1}$ bevacizumab and/or once daily with oral $2 \mathrm{mg} \mathrm{kg}^{-1}$ simvastatin dissolved in DW by pipette. (A) Tumour diameters were measured every 2-3 days, and graphical representation of tumour volumes on different days after treatment is shown. In all cases, the combination of bevacizumab and simvastatin resulted in a significantly reduced tumour volume compared with bevacizumab alone. Resected tumours are shown. (B) Immunohistochemical staining of resected tumour. The expression levels of CD31, angiopoietin2, BiP, and Hsp90 $\alpha$ were lowest in the bevacizumab and simvastatin combination group (size bar for CD31, $200 \mu \mathrm{m}$; for angiopoietin2, BiP, and Hsp90, $50 \mu \mathrm{m}$ ) (C) The immunoblot analysis of angiopoietin2, BiP, and Hsp90 $\alpha$ protein expression. All three protein levels were markedly decreased in the bevacizumab and simvastatin combination group.
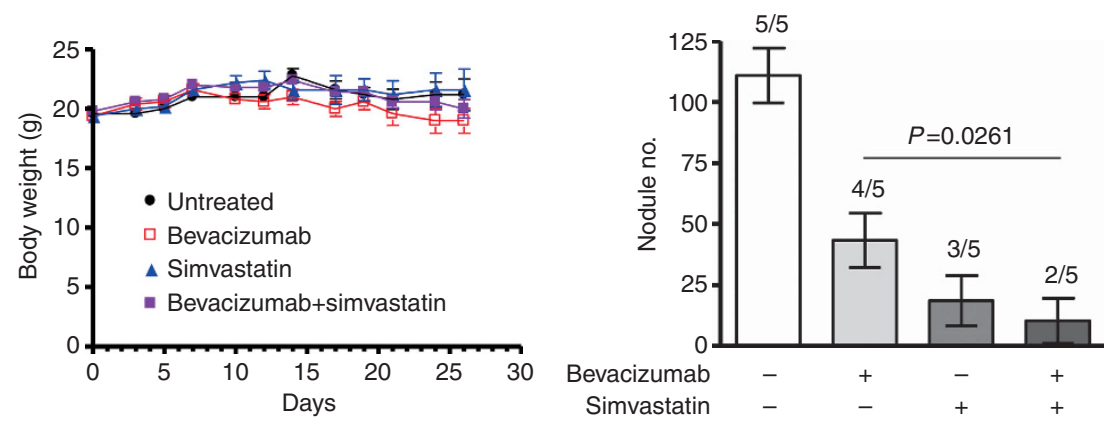

Figure 5. Effects of bevacizumab and simvastatin combination therapy on tumour metastases in vivo. BALB/c nude mice were inoculated intraperitoneally with $1.0 \times 10^{7}$ DLD1 cells and treated twice per week with intraperitoneal injection of $2.5 \mathrm{mg} \mathrm{kg}^{-1}$ bevacizumab and/or once daily with oral $2 \mathrm{mg} \mathrm{kg}^{-1}$ simvastatin dissolved in DW by pipette. After 4 weeks, animals were weighed and killed, and tumour nodules were counted. The rate of peritoneal tumour formation was 5 out of 5,4 out of 5,3 out of 5 , and 2 out of 5 in the untreated, bevacizumab, simvastatin, or bevacizumab and simvastatin combination group, respectively. The relative tumour number was decreased by $76 \%$ with the addition of simvastatin to bevacizumab treatment $(43.4$ vs $10.4 ; P=0.0261)$.

also illustrates that the protein expression levels of angiopoietin2, $\mathrm{BiP}$, and $\mathrm{Hsp} 90 \alpha$ in the bevacizumab and simvastatin combination group were markedly decreased, in concordance with the results of in vitro experiments shown in Figure 3.
After intraperitoneal injection of $1.0 \times 10^{7} \mathrm{DLD} 1$ cells in mice, peritoneal tumours were counted after 4 weeks. The rate of peritoneal tumour formation was 5 out of 5,4 out of 5,3 out of 5 , or 2 out of 5 in the untreated, bevacizumab, simvastatin, or 
bevacizumab and simvastatin combination group, respectively (Figure 5). The total number range of tumour nodules was 85-150 in the untreated group, 0-62 in the bevacizumab group, 0-53 in the simvastatin group, and $0-47$ in the bevacizumab and simvastatin combination group. The relative tumour number decreased by $76 \%$ with the addition of simvastatin to the bevacizumab treatment (43.4 vs $10.4 ; P=0.052$ ). It was also noted that the animal weight did not change in any of the four treatment groups.

\section{DISCUSSION}

In this study, we demonstrate that the addition of $0.2 \mu \mathrm{M}$ simvastatin to bevacizumab directly inhibits cell viability, invasion, and tube formation of HUVECs and also indirectly blocks invasion of HUVECs by suppressing angiogenesis-related mediators, such as angiopoietin2, $\mathrm{BiP}$, and $\mathrm{Hsp} 90 \alpha$ in CRC cells. These findings were verified by immunoblot assay, HUVEC invasion rescue, and siRNA assays. In a mouse model, the growth and metastasis of tumours were also significantly inhibited when simvastatin was added to bevacizumab. To the best of our knowledge, this report is the first to show not only the mechanism of action of simvastatin as an anti-angiogenic agent, but also the potential role of simvastatin in potentiating bevacizumab in CRC cells.

Several studies have suggested that the anti-angiogenic activity of statins is achieved by inhibiting proliferation and migration of endothelial cells, as well as inducing cell apoptosis (Negre-Aminou et al, 1997; Pirillo et al, 1997; Sato et al, 1998; Kaneta et al, 2003; Muck et al, 2004; Schaefer et al, 2004); however, these studies used high concentrations of statins ranging from 2 to $100 \mu \mathrm{M}$ in vitro. To reach serum concentrations of $2-20 \mu \mathrm{M}$, simvastatin has to be administered at a daily dose of $100-200 \mathrm{mg} \mathrm{kg}^{-1}$, a dose not feasible for human use. Therefore, in this study, we focused on the indirect anti-angiogenic effect of simvastatin at a cardiovascular therapeutic dose level in humans and found that simvastatin at this concentration suppressed several angiogenic mediators, thereby leading to the inhibition of HUVEC invasion. In agreement with our previous report that $0.2 \mu \mathrm{M}$ simvastatin enhanced the antitumour activity of cetuximab in CRC cells carrying KRAS mutations (Lee et al, 2011), here we demonstrate the therapeutic role of simvastatin at the dose typically used for hypercholesterolaemia. As statins are the most widely prescribed drugs for patients with hypercholesterolaemia and their toxicity profiles have been well established, the application of statins for cancer therapy is clinically realistic with minimal further effort and time. Indeed, we previously studied a daily simvastatin dose of $40 \mathrm{mg}$ in combination with irinotecan-based chemotherapy in CRC patients and found that this combination was safe with no additional toxicity (Lee et al, 2009).

Angiopoietin1 and angiopoietin2 are secreted factors that bind to the endothelial cell-specific receptor tyrosine kinase Tie2 and regulate angiogenesis. Angiopoietin1 activates Tie2 to promote blood vessel maturation and stabilisation (Davis et al, 1996; Suri et al, 1996; Augustin et al, 2009), whereas angiopoietin2 is thought to function largely as a Tie2 antagonist to promote tumour angiogenesis (Felcht et al, 2012; Daly et al, 2013). Angiopoietin2 expression is usually upregulated in a wide range of human cancers and is therefore a candidate target in many ongoing clinical trials (Currie et al, 2002; Lind et al, 2005; Park et al, 2007; Detjen et al, 2010; Gerald et al, 2013). Binding immunoglobulin protein, a member of the heat shock protein 70 (HSP70) family, is a multifunction protein that has a major role in protein processing in the endoplasmic reticulum (ER), protein quality control, ER homeostasis, as well as controlling cell signalling and viability (Ni and Lee, 2007). In a recent study, knockdown of BiP expression in immortalised human endothelial cells revealed that $\mathrm{BiP}$ is a critical mediator of angiogenesis (Dong et al, 2011). Molecular chaperone heat shock protein $90 \alpha$ (HSP90 $\alpha$ ) is critically involved in maintaining stability, integrity, and functions of key oncogenic proteins and has gained a lot of attention as a molecular target of cancer therapy (Young et al, 2001; Picard, 2002). Recent studies reported that inhibition of HSP90 resulted in suppression of angiogenesis, and that HSP90 had 'indirect' angiogenic effects (Moser et al, 2012).

However, our study has a few limitations. Although we attempted to focus on the anti-angiogenic effects of simvastatin, it was difficult to create an angiogenesis xenograft model. We only showed that simvastatin potentiated anti-growth effects of bevacizumab in vivo. To fill the gap, we employed a peritonealseeding xenograft model and demonstrated similar results. Future studies are needed to define the mechanism of action of simvastatin in modulating angiopoietin2, BiP, and HSP $90 \alpha$.

The results of this study indicate that the addition of simvastatin at a dose used in patients with cardiovascular diseases $(40-80 \mathrm{mg}$ once daily) may potentiate the anti-angiogenic effects of bevacizumab on CRC by suppressing angiopoietin2, BiP, and $\mathrm{Hsp} 90 \alpha$ in cancer cells. On the basis of these preclinical studies, we are planning a phase II study to evaluate the effect of a combination of simvastatin with bevacizumab, capecitabine, and oxaliplatin as a first-line treatment for metastatic CRC patients.

\section{ACKNOWLEDGEMENTS}

This work was supported by grants from the Samsung Biomedical Research Institute (GL1-B2-011-1) and the Korean Health Technology R\&D Project, Ministry of Health \& Welfare, Republic of Korea (A102166).

\section{CONFLICT OF INTEREST}

The authors declare no conflict of interest.

\section{AUTHOR CONTRIBUTIONS}

WK Kang conceived and designed the study and supervised the research; I Lee performed the majority of experiments; SJ Lee offered assistance with some experiments and wrote the manuscript; J Lee provided comments on the manuscript; and C Park supervised the research.

\section{REFERENCES}

Assmus B, Urbich C, Aicher A, Hofmann WK, Haendeler J, Rossig L, Spyridopoulos I, Zeiher AM, Dimmeler S (2003) HMG-CoA reductase inhibitors reduce senescence and increase proliferation of endothelial progenitor cells via regulation of cell cycle regulatory genes. Circ Res 92: 1049-1055.

Augustin HG, Koh GY, Thurston G, Alitalo K (2009) Control of vascular morphogenesis and homeostasis through the angiopoietin-Tie system. Nat Rev Mol Cell Biol 10: 165-177.

Casey PJ (1995) Protein lipidation in cell signaling. Science 268: 221-225.

Currie MJ, Gunningham SP, Turner K, Han C, Scott PA, Robinson BA, Chong W, Harris AL, Fox SB (2002) Expression of the angiopoietins and their receptor Tie2 in human renal clear cell carcinomas; regulation by the von Hippel-Lindau gene and hypoxia. J Pathol 198: 502-510.

Daly C, Eichten A, Castanaro C, Pasnikowski E, Adler A, Lalani AS, Papadopoulos N, Kyle AH, Minchinton AI, Yancopoulos GD, Thurston G (2013) Angiopoietin-2 functions as a Tie2 agonist in tumor models, where it limits the effects of VEGF inhibition. Cancer Res 73: 108-118.

Davis S, Aldrich TH, Jones PF, Acheson A, Compton DL, Jain V, Ryan TE, Bruno J, Radziejewski C, Maisonpierre PC, Yancopoulos GD (1996) 
Isolation of angiopoietin-1, a ligand for the TIE2 receptor, by secretiontrap expression cloning. Cell 87: 1161-1169.

Detjen KM, Rieke S, Deters A, Schulz P, Rexin A, Vollmer S, Hauff P, Wiedenmann B, Pavel M, Scholz A (2010) Angiopoietin-2 promotes disease progression of neuroendocrine tumors. Clin Cancer Res 16: $420-429$.

Dimmeler S, Aicher A, Vasa M, Mildner-Rihm C, Adler K, Tiemann M, Rutten H, Fichtlscherer S, Martin H, Zeiher AM (2001) HMG-CoA reductase inhibitors (statins) increase endothelial progenitor cells via the PI 3-kinase/Akt pathway. J Clin Invest 108: 391-397.

Dong D, Stapleton C, Luo B, Xiong S, Ye W, Zhang Y, Jhaveri N, Zhu G, Ye R, Liu Z, Bruhn KW, Craft N, Groshen S, Hofman FM, Lee AS (2011) A critical role for GRP78/BiP in the tumor microenvironment for neovascularization during tumor growth and metastasis. Cancer Res 71: 2848-2857.

Felcht M, Luck R, Schering A, Seidel P, Srivastava K, Hu J, Bartol A, Kienast Y, Vettel C, Loos EK, Kutschera S, Bartels S, Appak S, Besemfelder E, Terhardt D, Chavakis E, Wieland T, Klein C, Thomas M, Uemura A, Goerdt S, Augustin HG (2012) Angiopoietin-2 differentially regulates angiogenesis through TIE2 and integrin signaling. J Clin Invest 122: 1991-2005.

Ferrara N (2002) VEGF and the quest for tumour angiogenesis factors. Nat Rev Cancer 2: 795-803.

Folkman J (1971) Tumor angiogenesis: therapeutic implications. N Engl J Med 285: $1182-1186$.

Folkman J (2007) Angiogenesis: an organizing principle for drug discovery? Nat Rev Drug Discov 6: 273-286.

Gerald D, Chintharlapalli S, Augustin HG, Benjamin LE (2013) Angiopoietin2: an attractive target for improved antiangiogenic tumor therapy. Cancer Res 73(6): 1649-1657.

Giantonio BJ, Catalano PJ, Meropol NJ, O'Dwyer PJ, Mitchell EP, Alberts SR, Schwartz MA, Benson 3rd AB (2007) Bevacizumab in combination with oxaliplatin, fluorouracil, and leucovorin (FOLFOX4) for previously treated metastatic colorectal cancer: results from the Eastern Cooperative Oncology Group Study E3200. J Clin Oncol 25: 1539-1544.

Goldstein JL, Brown MS (1990) Regulation of the mevalonate pathway. Nature 343: 425-430.

Grothey A, Sugrue MM, Purdie DM, Dong W, Sargent D, Hedrick E, Kozloff M (2008) Bevacizumab beyond first progression is associated with prolonged overall survival in metastatic colorectal cancer: results from a large observational cohort study (BRiTE). J Clin Oncol 26: 5326-5334.

Hurwitz H, Fehrenbacher L, Novotny W, Cartwright T, Hainsworth J, Heim W, Berlin J, Baron A, Griffing S, Holmgren E, Ferrara N, Fyfe G, Rogers B, Ross R, Kabbinavar F (2004) Bevacizumab plus irinotecan, fluorouracil, and leucovorin for metastatic colorectal cancer. N Engl J Med 350: $2335-2342$.

Kaneta S, Satoh K, Kano S, Kanda M, Ichihara K (2003) All hydrophobic HMG-CoA reductase inhibitors induce apoptotic death in rat pulmonary vein endothelial cells. Atherosclerosis 170: 237-243.

Kim WS, Kim MM, Choi HJ, Yoon SS, Lee MH, Park K, Park CH, Kang WK (2001) Phase II study of high-dose lovastatin in patients with advanced gastric adenocarcinoma. Invest New Drugs 19: 81-83.

Lee J, Jung KH, Park YS, Ahn JB, Shin SJ, Im SA, Oh do Y, Shin DB, Kim TW, Lee N, Byun JH, Hong YS, Park JO, Park SH, Lim HY, Kang WK (2009) Simvastatin plus irinotecan, 5-fluorouracil, and leucovorin (FOLFIRI) as first-line chemotherapy in metastatic colorectal patients: a multicenter phase II study. Cancer Chemother Pharmacol 64: 657-663.

Lee J, Lee I, Han B, Park JO, Jang J, Park C, Kang WK (2011) Effect of simvastatin on cetuximab resistance in human colorectal cancer with KRAS mutations. J Natl Cancer Inst 103: 674-688.

Lee J, Lee I, Park C, Kang WK (2006) Lovastatin-induced RhoA modulation and its effect on senescence in prostate cancer cells. Biochem Biophys Res Commun 339: 748-754.

Lind AJ, Wikstrom P, Granfors T, Egevad L, Stattin P, Bergh A (2005) Angiopoietin 2 expression is related to histological grade, vascular density, metastases, and outcome in prostate cancer. Prostate 62: 394-399.

Llevadot J, Murasawa S, Kureishi Y, Uchida S, Masuda H, Kawamoto A, Walsh K, Isner JM, Asahara T (2001) HMG-CoA reductase inhibitor mobilizes bone marrow-derived endothelial progenitor cells. J Clin Invest 108: $399-405$.

Moser C, Lang SA, Hackl C, Wagner C, Scheiffert E, Schlitt HJ, Geissler EK, Stoeltzing O (2012) Targeting HSP90 by the novel inhibitor NVP-AUY922 reduces growth and angiogenesis of pancreatic cancer. Anticancer Res 32: 2551-2561.

Muck AO, Seeger H, Wallwiener D (2004) Class-specific pro-apoptotic effect of statins on human vascular endothelial cells. Z Kardiol 93: 398-402.

Negre-Aminou P, van Vliet AK, van Erck M, van Thiel GC, van Leeuwen RE, Cohen LH (1997) Inhibition of proliferation of human smooth muscle cells by various HMG-CoA reductase inhibitors; comparison with other human cell types. Biochim Biophys Acta 1345: 259-268.

Ni M, Lee AS (2007) ER chaperones in mammalian development and human diseases. FEBS Lett 581: 3641-3651.

Park C, Lee I, Kang WK (2001) Lovastatin-induced E2F-1 modulation and its effect on prostate cancer cell death. Carcinogenesis 22: 1727-1731.

Park JH, Park KJ, Kim YS, Sheen SS, Lee KS, Lee HN, Oh YJ, Hwang SC (2007) Serum angiopoietin-2 as a clinical marker for lung cancer. Chest 132: 200-206

Picard D (2002) Heat-shock protein 90, a chaperone for folding and regulation. Cell Mol Life Sci 59: 1640-1648.

Pirillo A, Jacoviello C, Longoni C, Radaelli A, Catapano AL (1997) Simvastatin modulates the heat shock response and cytotoxicity mediated by oxidized LDL in cultured human endothelial smooth muscle cells. Biochem Biophys Res Commun 231: 437-441.

Sato I, Ma L, Ikeda M, Morita I, Murota S (1998) Simvastatin, a potent HMG-CoA reductase inhibitor, inhibits the proliferation of human and bovine endothelial cells in vitro. J Atheroscler Thromb 4: 102-106.

Schaefer CA, Kuhlmann CR, Gast C, Weiterer S, Li F, Most AK, Neumann T, Backenkohler U, Tillmanns H, Waldecker B, Wiecha J, Erdogan A (2004) Statins prevent oxidized low-density lipoprotein- and lysophosphatidylcholine-induced proliferation of human endothelial cells. Vascul Pharmacol 41: 67-73.

Spyridopoulos I, Haendeler J, Urbich C, Brummendorf TH, Oh H, Schneider MD, Zeiher AM, Dimmeler S (2004) Statins enhance migratory capacity by upregulation of the telomere repeat-binding factor TRF2 in endothelial progenitor cells. Circulation 110: 3136-3142.

Suri C, Jones PF, Patan S, Bartunkova S, Maisonpierre PC, Davis S, Sato TN, Yancopoulos GD (1996) Requisite role of angiopoietin-1, a ligand for the TIE2 receptor, during embryonic angiogenesis. Cell 87: $1171-1180$.

Van Cutsem E, Rivera F, Berry S, Kretzschmar A, Michael M, DiBartolomeo M, Mazier MA, Canon JL, Georgoulias V, Peeters M, Bridgewater J, Cunningham D (2009) Safety and efficacy of first-line bevacizumab with FOLFOX, XELOX, FOLFIRI and fluoropyrimidines in metastatic colorectal cancer: the BEAT study. Ann Oncol 20: 1842-1847.

Vivo C, Lecomte C, Levy F, Leroy K, Kirova Y, Renier A, Kheuang L, Piedbois P, Chopin D, Jaurand MC (2003) Cell cycle checkpoint status in human malignant mesothelioma cell lines: response to gamma radiation. Br J Cancer 88: 388-395.

Weis M, Heeschen C, Glassford AJ, Cooke JP (2002) Statins have biphasic effects on angiogenesis. Circulation 105: 739-745.

Young JC, Moarefi I, Hartl FU (2001) Hsp90: a specialized but essential protein-folding tool. J Cell Biol 154: 267-273.

This work is published under the standard license to publish agreement. After 12 months the work will become freely available and the license terms will switch to a Creative Commons AttributionNonCommercial-Share Alike 3.0 Unported License.

Supplementary Information accompanies this paper on British Journal of Cancer website (http://www.nature.com/bjc) 